\title{
Creating a Competitive Advantage in the UK Higher Education Sector through Mirrored Course Delivery: A case example
}

\author{
By Dr. Elizabeth Spruin \\ Department of Psychology, Canterbury Christ Church University
}

\begin{abstract}
Address for Correspondence:
Dr. Elizabeth Spruin

Department of Psychology

Canterbury Christ Church University

Canterbury, Kent
\end{abstract}

CT1 1QU

England

E-mail: Liz.Spruin@canterbury.ac.uk.

\begin{abstract}
Utilising Canterbury Christ Church University (CCCU) as a case example, this report will provide information about the strategic challenges that many modern universities in the UK face in creating a flexible delivery of education. Using strategic concepts and analysis, the current short report will examine the competitiveness within the higher education sector in the UK and explore key external and internal environmental factors of CCCU, gaining a greater understanding of their current position. From these analyses, strategic recommendations as to how universities such as CCCU can create a competitive advantage through a new form of flexible learning delivery.

Keywords: higher education; competitive advantage; PEST analysis; strategic planning; SWOT analysis
\end{abstract}




\section{INTRODUCTION}

The higher education sector in the UK faces a number of challenges in its pursuit for a sustainable future. Even before the sector was propelled into the Covid-19 crisis, there have been compelling arguments for universities to become more adaptable due to the uncertainty of the economy (Murray \& Matthew, 2018). With the reduction of government funding, the increase in globalisation and the uncertainty that Brexit brings, the emergence of the recent pandemic has fundamentally shifted the landscape of higher education, further exacerbating the need for universities to adapt to this unstable and fast-changing environment (Hillman, 2020). Accordingly, the future of higher education lies within the capacity of universities to build adaptability into their operations, enabling them to not only respond more swiftly to rapid changes in the environment, but also allowing them to plan more effectively for the future (Reupert, 2020).

With these transformations on the horizon, one of the greatest strategic challenges facing universities, will be adapting current learning and teaching models to create more flexibility, while also ensuring they maintain a distinctive competitive advantage within the sector (Baxter \& Atlas, 2020). For modern institutes such as Canterbury Christ Church University (CCCU), which tends to attract students from the local South East region and prides itself on being a local university for the community, this challenge will require a bold restructure of the organisation's current pedagogy and reliance on the university's distinctive resources and capabilities.

\section{METHODOLOGY}

To address the purpose of this report, which is to evaluate the CCCU's current position in adopting a flexible learning environment and generate strategic recommendations for the future, the methodology used was adapted from the Layers of the Business Environment Framework (Johnson et al., 2018). More specifically, as the recommended outcomes from this report focus on enhancing the competitive advantage of CCCU, it is essential that the two main groups of competitive advantage, the organisation's position and its capabilities (Saloner et al., 2001), are rigorously analysed. This will ensure that any strategic options 
found reflect the university's place in the external environment, while also considering any internal resources which create value. This methodology further aligns with the research on developing effective strategies (e.g., Vignali \& Vrontis, 2004), which contends that successful strategies cannot be created without analysing the external environment and industry sector for which an organisation operates, along with the internal environment resources. Accordingly, the analysis for this report was carried out in four distinct stages:

1) External environment analysis. Using a mixed methodology of published sources (e.g., annual reports, policies and papers, media articles, etc) and direct discussions with academics and managers, a PESTLE analysis (Aguilar, 1967) was carried out to examine the external macro-environment of the organisation, focusing on key drivers of structural change. This analysis thereby identified possible threats within the environment, along with opportunities for potential growth (Johnson \& Scholes, 2008).

2) Industry analysis. To gain a comprehensive awareness of the industry in which CCCU operates, a Porter's Five Forces analysis was conducted (Porter,1980). This analysis assessed and evaluated the competitive strength and position of the university within the sector and also helped to further identify any potential areas of competitive advantage.

3) Organisation analysis. To develop a thorough understanding into the internal and external factors affecting the university, a weighted SWOT analysis (Humphrey, 2005) was performed using LaConte's (2017) weighted scoring method. This approach incorporated the impact and importance of each SWOT factor, along with the relative probability of each factor, with those factors that score higher overall being areas of priority. This method therefore allowed for a comprehensive analysis of SWOT factors, with strategic insight into critical areas of focus for the strategic recommendations.

4) Strategic Options. The relationships between the SWOT factors were then investigated via a TOWS Matrix (Weihrich, 1982). The TOWS framework has shown 
to be an effective tool for strategic planning and an important step for developing appropriate strategies (Fleisher \& Bensoussan, 2003). For the current report, the analysis helped to establish coherency between the internal (strengths and weaknesses) and external (opportunities and threats) factors from the SWOT, helping to identify relevant strategic options for the university to pursue.

The strategic recommendations reported were then generated from the analysed output using a Resource-Based View (RBV; Wernerfelt, 1984). This approach was chosen to ensure the feasibility of the strategic recommendations and implementation plan, focusing on existing resources in an innovative way to exploit opportunities. Figure 1 below demonstrates the process of strategic analysis that was carried out for this report and how the recommendations generated will enhance the current position of the university. 


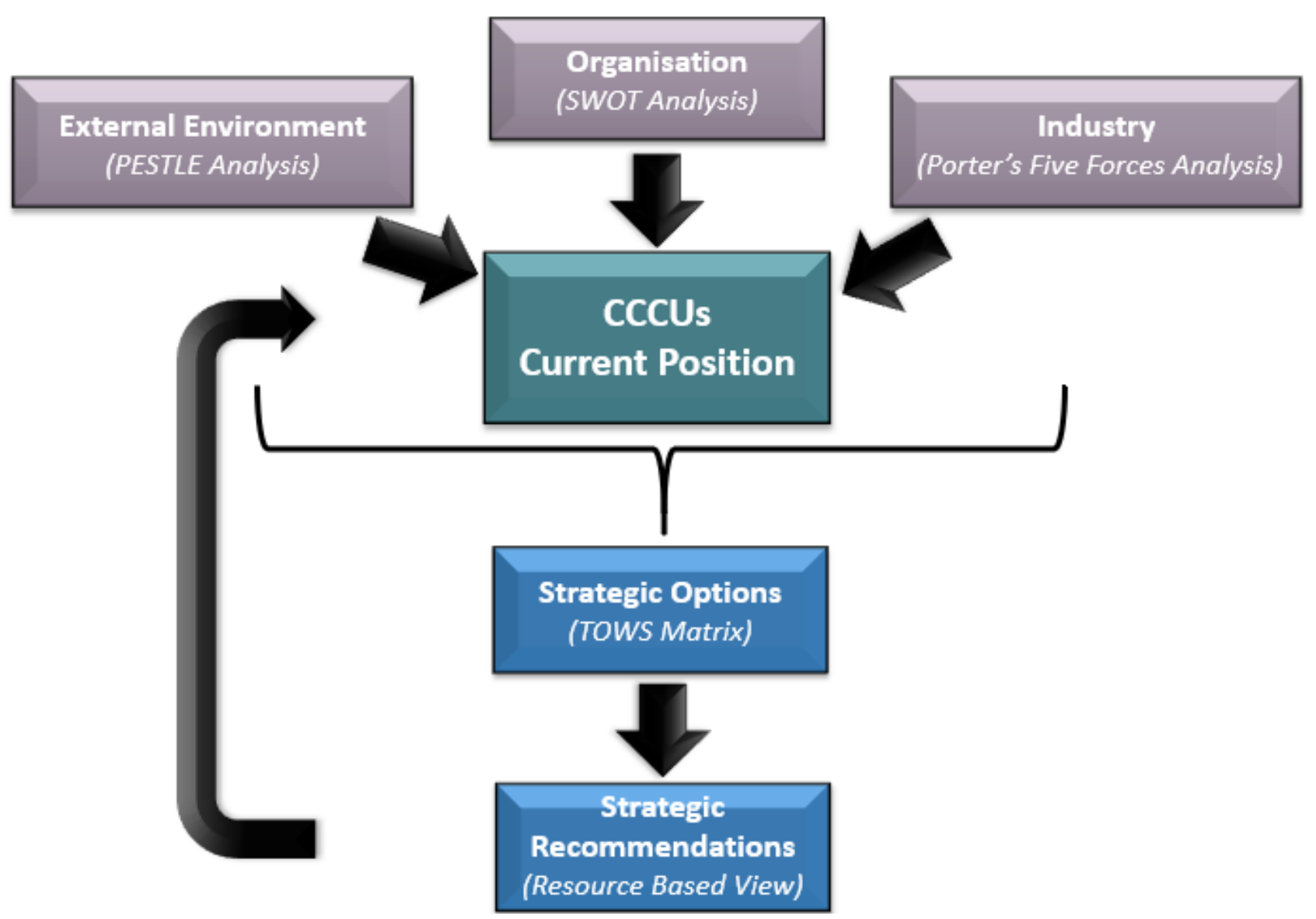

Figure 1. Process of strategic analysis

\section{FINDINGS}

External Environment Analysis (PESTLE)

The findings from the PESTLE analysis (Aguilar, 1967) are summarised in Table 1 below. The analysis focused on the key drivers for change in the higher education sector in relation to the flexible delivery of education, as shown below no significant Legal or Ecological factors were identified. 


\begin{tabular}{|c|c|c|c|}
\hline & External Issues & Opportunities & Threats \\
\hline \multirow{3}{*}{$\begin{array}{c}\text { P } \\
\text { (Political) }\end{array}$} & $\begin{array}{l}\text { Reduction in } \\
\text { funding }\end{array}$ & $\begin{array}{l}\text { - Incentive to find new markets } \\
\text { for alternative sources of } \\
\text { revenue }\end{array}$ & $\begin{array}{l}\text { - Impact on the sustainability } \\
\text { of resources and capabilities }\end{array}$ \\
\hline & Impact of Brexit & $\begin{array}{l}\text { - Reduced competition for UK } \\
\text { students - Opportunity to focus } \\
\text { on UK student market }\end{array}$ & - Income reduction from EU \\
\hline & $\begin{array}{l}\text { Government } \\
\text { initiatives - } \\
\text { Skills for Jobs }\end{array}$ & $\begin{array}{l}\text { - New areas for portfolio } \\
\text { development }\end{array}$ & $\begin{array}{l}\text { - Increased competition } \\
\text { between higher and further } \\
\text { education establishments }\end{array}$ \\
\hline $\begin{array}{c}\text { E } \\
\text { (Economical) }\end{array}$ & $\begin{array}{l}\text { Recession } \\
\text { arising from } \\
\text { pandemic }\end{array}$ & $\begin{array}{l}\text { - Increase in re-training needs due } \\
\text { to poor job market }\end{array}$ & $\begin{array}{l}\text { - Financial instability - mature } \\
\text { students }\end{array}$ \\
\hline $\begin{array}{c}\text { S } \\
\text { (Social) }\end{array}$ & Cultural trends & $\begin{array}{l}\text { Opportunity to create new } \\
\text { flexible, non-linear, pathways - } \\
\text { help reduce student pressures } \\
\text { and widen participation. } \\
\text { - Increase interest in STEM } \\
\text { subjects }\end{array}$ & $\begin{array}{l}\text { - Increase in student well- } \\
\text { being and mental health } \\
\text { issues } \\
\text { - BAME attainment gap }\end{array}$ \\
\hline
\end{tabular}

Table 1. Summary of PESTEL factors and their influence on the higher education sector in the UK

\section{Industry Analysis (Porter's Five Forces)}

As shown in the figure below (see Figure 2), the results from Porter's Five Forces (Porter, 1980), as applied to the higher education sector in the UK, indicates that the main threat to the industry are from substitutes, which offer similar courses to CCCU. The risk of this threat is exacerbated further by the high power of applicants in the industry, as they can easily switch providers if unsatisfied with their institution. 


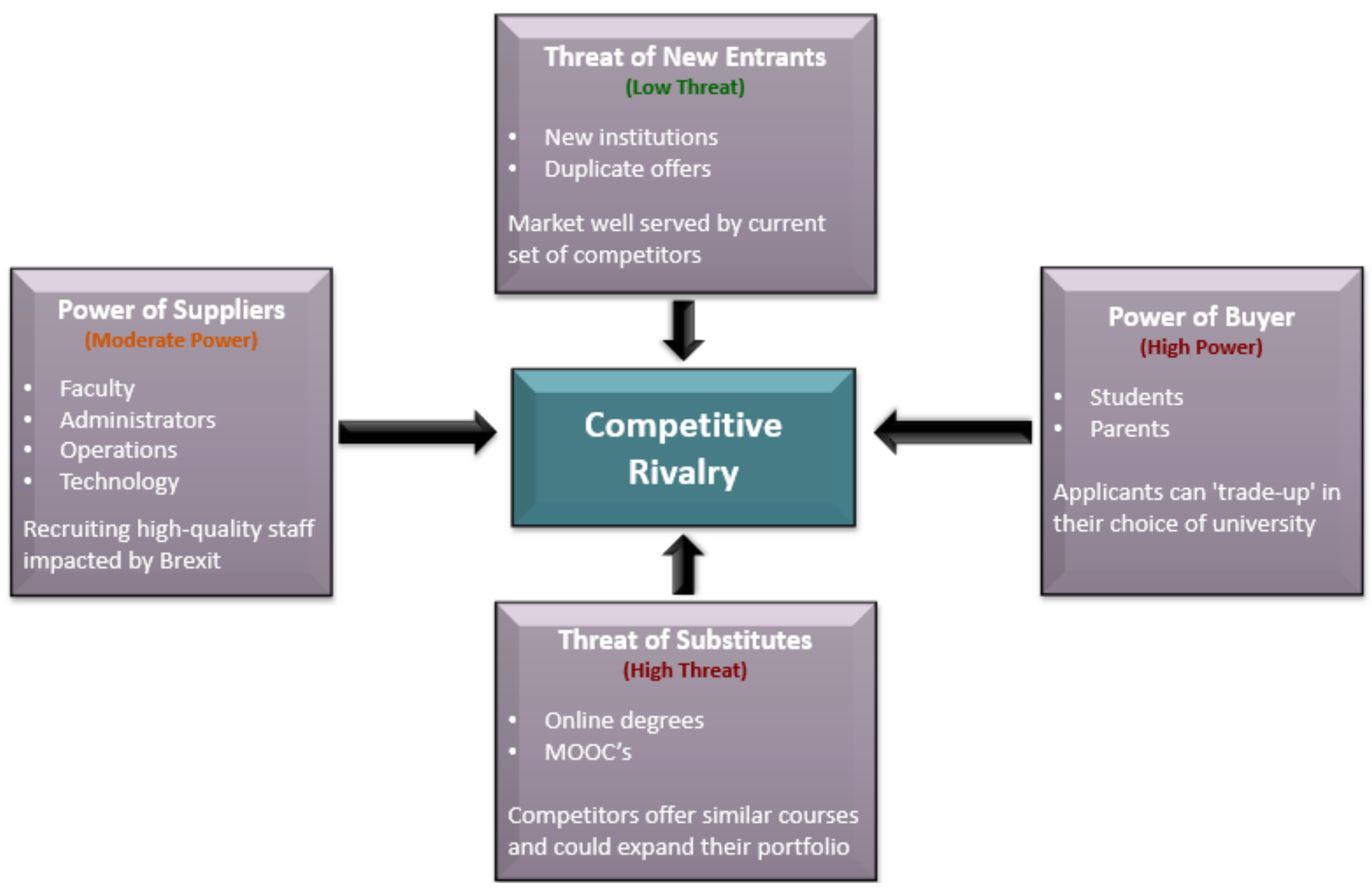

Figure 2. Porter's Five Forces - Higher Education Sector

\section{Organisation Analysis (SWOT)}

The SWOT factors found in the analysis were identified via a brainstorming session (see Lu, 2010) with the researcher and several senior CCCU staff members from various disciplines.

Findings are summarised in Figure 3 below, with the weighted analysis identifying critical areas of focus for each SWOT factor. These key areas were also highlighted in the environment and industry analysis. 


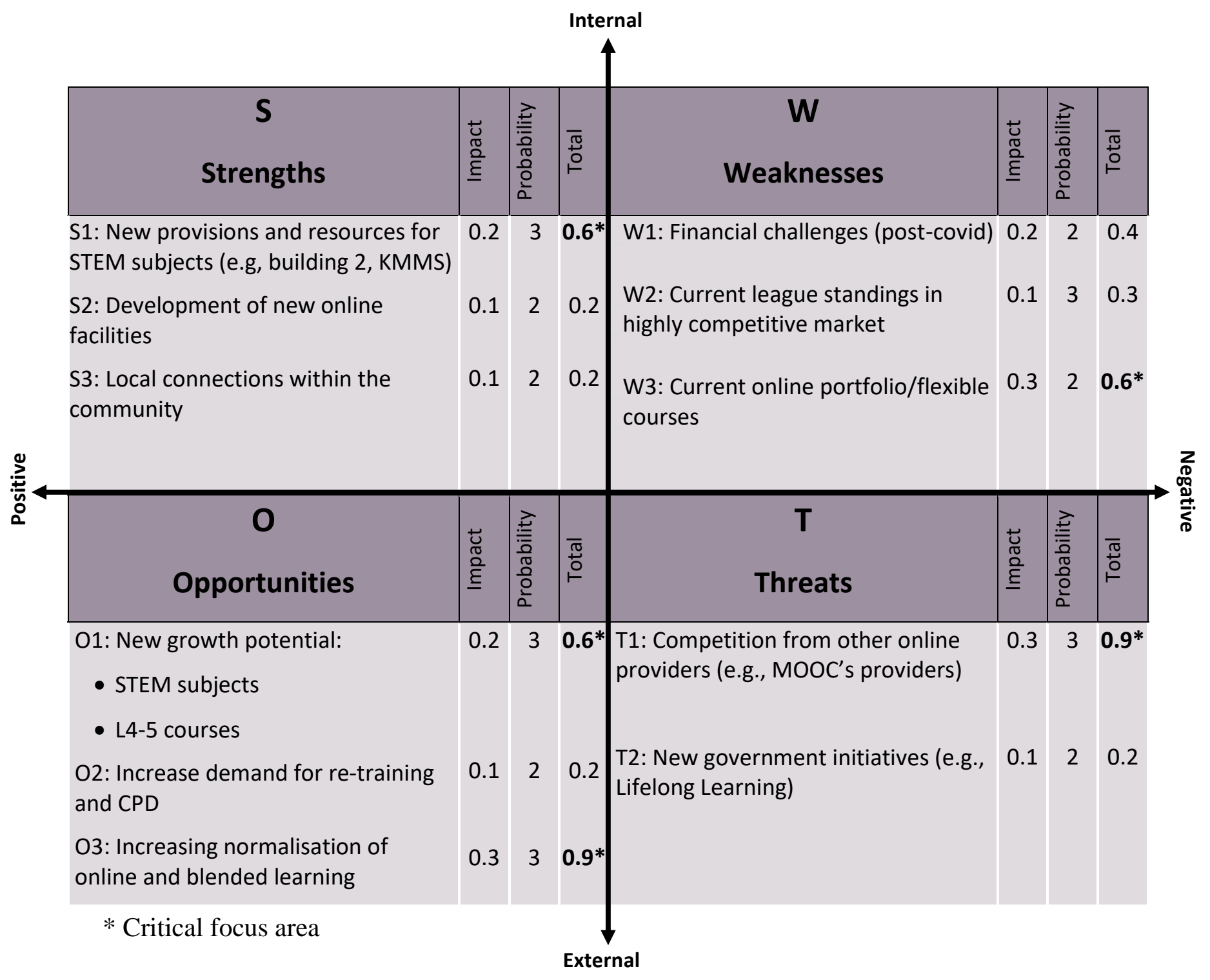

Figure 3. SWOT Analysis: * highlighting the critical focus areas - S1, W3, O1, T1

\section{Strategic Options (TOWS Matrix)}

To systematically identify any strategic options from the SWOT analysis (see Figure 3 above), the internal (strengths and weaknesses) and external (opportunities and threats) points were first connected to visually highlight any relationships between factors (see Yavuz \& Baycan, 2013). A graphical representation of the key relationships that were found is presented below (see Figure 4). 


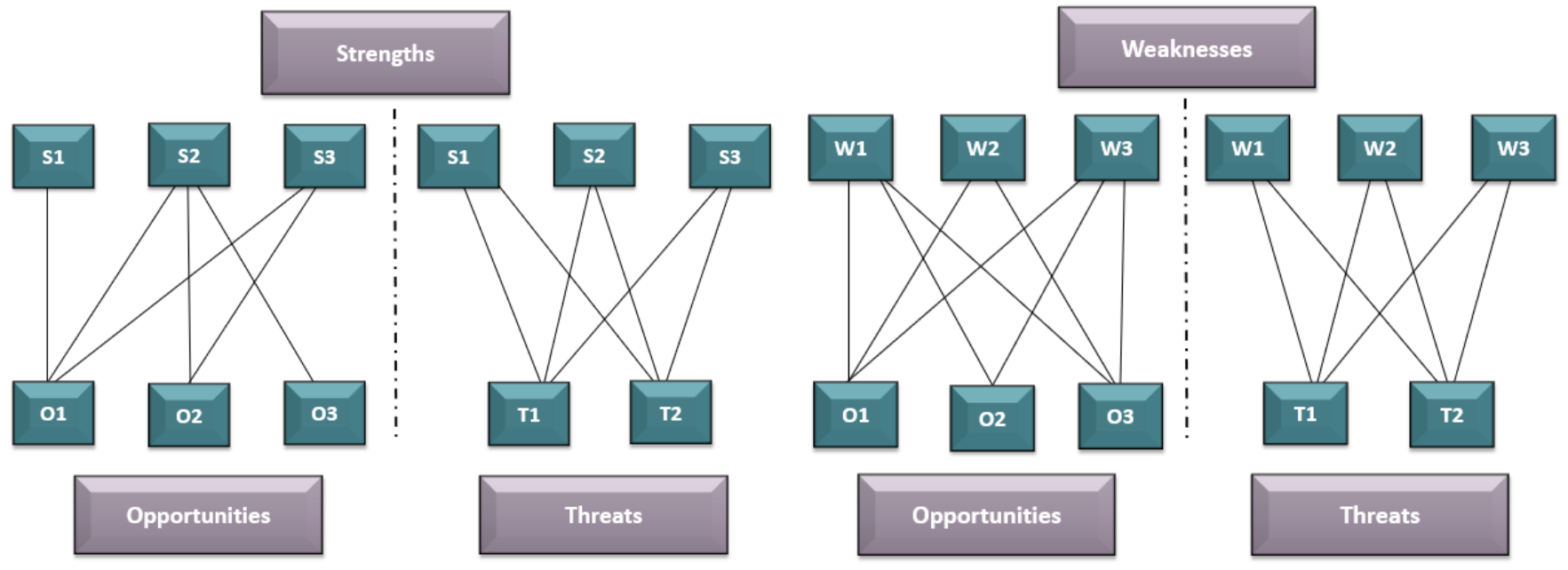

Figure 4. SWOT Analysis - Relationships between Internal and External Factors

The relationships that were identified above were then utilised to develop corresponding strategies for the university via a TOWS matrix. As shown in the Table 2 below, by combining the internal strengths and weaknesses of the university with the external opportunities and threats, four strategic themes emerged which identified a number of strategic options. Those strategic options that correspond to one of the critical areas identified in the SWOT are the key areas of focus.

\section{Strengths \\ (Internal, Positive) \\ Strengths - Opportunities \\ (SO Strategies)}

1. **S1, S2 \& S3 to 01:

- Use online facilities to develop new blended learning provisions, with a focus on L4-5 courses in STEM subjects.

- Capitalise on local STEM connections Opportunities (External, Positive) to collaborate on new course development.

2. $\mathrm{S} 2$ \& $\mathrm{S} 3$ to 02 :

- In collaboration with local organisations, develop new blended learning courses, to capitalise on the growing need for re-training.

\section{Weaknesses}

(Internal, Negative)

\section{Weaknesses-Opportunities (WO Strategies)}

1. ${ }^{* *} \mathbf{W} 1, \mathbf{W} 2$ \& $\mathbf{W} 3$ to $01:$

- Take advantage of areas for potential market growth by:

o Creating new sources of revenue via blended learning provisions to minimise financial challenges.

o Building a new reputation for CCCU outside the current league tables.

o Focus on developing innovative blended learning provisions in STEM subjects to improve current online portfolio.

2. W1 \& W3 to 02: 


\section{S2 to 03:}

- Implement an innovative approach to blended learning delivery to capitalise on opportunities and sustain a competitive advantage.

\section{Strengths - Threats \\ (ST Strategies)}

\section{Threats}

(External, Negative)

- Minimise threat from other providers

- Capitalise on the growing need for retraining and upskilling by extending current online course portfolio.

\section{W1, W2 \& W3 to 03:}

- Minimise weaknesses by capitalising on the normalisation of online and blended learning.

- Creating innovative blended learning courses to reduce financial challenges and rebrand reputation in new online market.

$\frac{\text { Weaknesses-Threats }}{\text { (WT Strategies) }}$

1. **W1, W2 \& $\mathrm{W} 3$ to $\mathrm{T} 1:$

- Avoid threats from other providers by utilising new online resources to create an innovative approach to blended learning, with a focus on STEM subjects and helping rebuild the local community.

2. S1, S2 \& S3 to T2:

- Use online provisions and STEM resources to help capitalise on new government initiatives and reduce the threat from other providers.

- Focus on lifelong learning within the local South East England community. and minimise weaknesses by utilising strengths to create an innovative approach to blended learning, within reputable areas of the university (e.g., STEM subjects).

2. W1, W2 \& W3 to T2:

- Utilise 'SO' strategies to capitalise on governments lifelong learning initiative. This would avoid immediate threats and provide incentive for the university to develop areas of weakness to take advantage of new market.

Table 2. TOWS Analysis: Strategic Options - ** highlighting the strategies that correspond to the critical focus areas (S1, W3, O1, T1).

\section{STRATEGIC RECOMMENDATIONS}

Based on the presented findings, in order for CCCU to create a flexible delivery of education and also ensure they maintain a distinctive competitive advantage within the sector, they need to implement the strategic options found within the critical focus areas (S1, W3, O1, T1). In particular, to avoid threats from other online providers and minimise weaknesses, the university needs to capitalise on new market opportunities by developing innovative 
blended learning provisions, starting with a focus on STEM subjects and level 4-5 courses. This will enable the university to feasibly exploit external opportunities through utilising existing resources in a new way, creating a new reputation for CCCU outside the current league tables and placing them at a sustained competitive advantage.

Due to the high threat from other universities offering similar flexible learning provisions (see figure 2 above), a key component to the success of these recommendations will be the implementation of an innovative blended learning provision. More specifically, in the 2020/21 academic year, $98 \%$ of universities adopted blended learning provisions, this trend is expected to continue, with future projections in 2030 indicating that $70 \%$ of universities will continue to implement blended learning provisions (JISC, 2020). To create a competitive advantage in this growing market, it is recommended that CCCU introduce an innovative approach to programme delivery by offering students the choice of either a standard on-campus learning experience or a fully digital distance learning experience, which offers more flexibility for students to learn alongside other commitments. The flexibility of this provision would not only provide a location-independent alternative for students who are keen to undertake courses online, but the structure would mirror the face-to-face route, providing students with a choice as to the mode of delivery they would prefer, and the opportunity to transfer from one mode to another if their circumstances change during.

Providing this unique type of flexibility would thus capitalise on the opportunities that have come from the normalisation of online/blended learning and also defend against threats from other competitors, creating unequivocal value for the university. As this type of mirrored delivery would be the first of its kind in the UK, the approach would also be a resource which only CCCU would possess, making it truly unique and rare. To ensure this approach is feasible during the initial development phase and sustains a competitive advantage for CCCU, the strengths of the university's imitable STEM resources will be exploited. With the mirrored delivery approach focusing on level 4-5 courses in STEM subjects. Utilising the STEM resources within the new Verena Holmes building, CCCU can utilise these tangible assets to build a new reputation outside the current league tables as a university that specialises in mirrored learning delivery in STEM subjects. The new 
reputation that CCCU would create as the innovative leaders in mirrored learning and STEM subjects, would be an intangible asset which CCCU could build on for future growth of mirrored learning provisions in other subject areas. Furthermore, by starting with a focus on level 4-5 courses in STEM subjects, it will allow the university to gradually and feasibly build on the processes and structures required to capitalise fully on the opportunities of the market (see Figure 5 below for outline implementation).

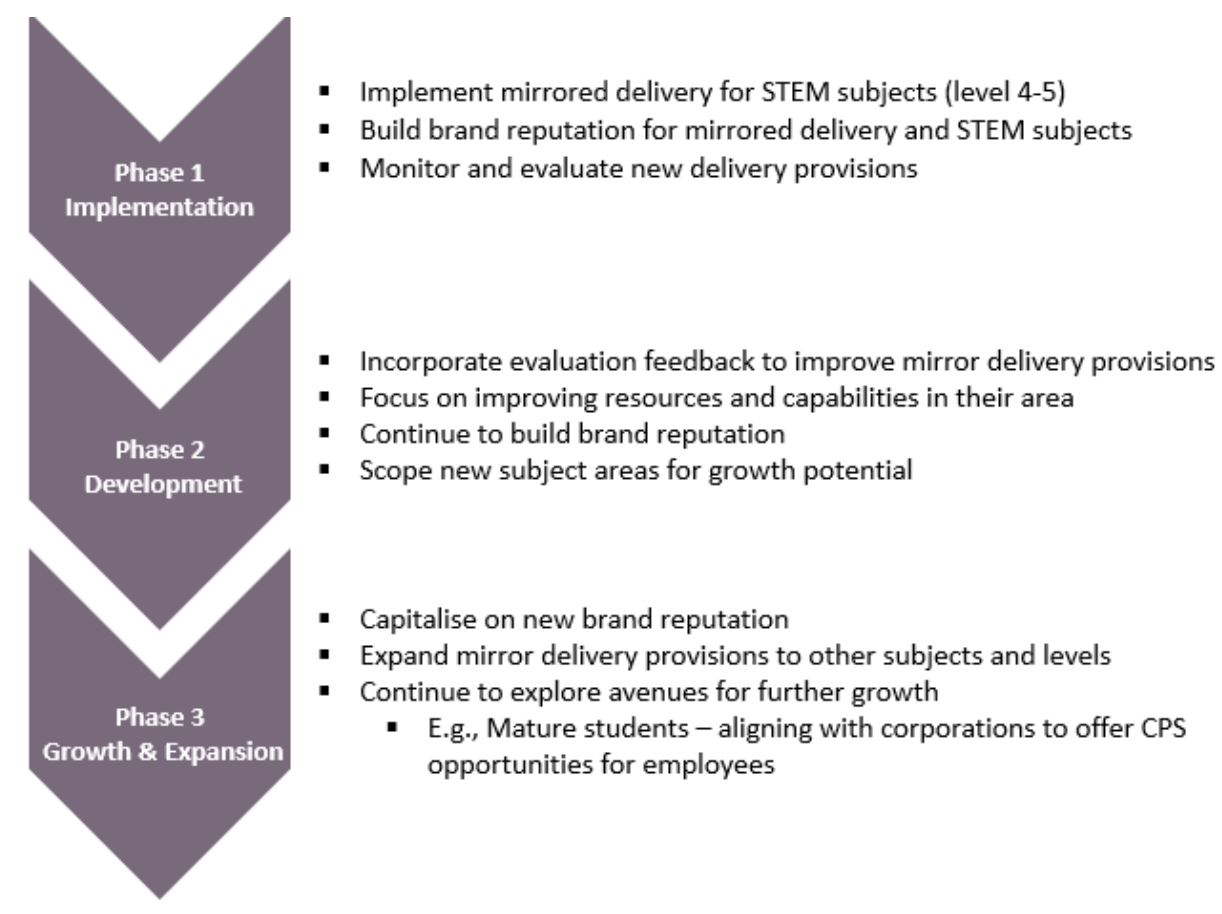

Figure 5. Implementation and growth of mirrored delivery approach

\section{Mirrored Delivery: Structure and Implementation}

The structure for this new provision would mean that there are two student cohorts: oncampus and distance learning. Both cohorts will have the same content and learning outcomes but will be delivered through different modes of delivery. For on-campus delivery, the existing STEM resources (e.g, Verena Holmes building) will be utilised to their full use, with no additional resources required to implement the new provisions. The distance learning delivery will utilise existing university platforms for distance learning (e.g., Blackboard Collaborate, Sway software, Padelt, etc), making full and extended use of these resources. For instance, the use of Padlet will provide students with a collaborative space to give input and engage in co-creation, Pebblepad will support students in reflective practice and portfolio related activities, and Kaltura will provide support for student presentations. 
The digital aspect of the distance learning mode will involve asynchronous learning, supported by weekly synchronic webinars, virtual drop-ins and tutorials. With a focus on STEM subjects, virtual labs will also be set-up to reflect an on-campus lab experience (see Figure 6 below for set-up). This set-up would therefore provide distance learning students the opportunity to learn in a mirrored version of the on-campus learners. The overall design of this approach embeds a sound pedagogical framework (Bates, 2017) and has also been successfully trialled by a number of programmes (e.g. Psychology) when delivering offcampus teaching during the pandemic.

Figure 6. Virtual lab set-up for distance learners. Virtual labs will be set-up on Blackboard collaborate, mirroring an on-campus lab experience. The set-up will include a combination of demonstrations in the 'main room', a 'break-out groupwork' area for collaborative student work and a 'help room' for students to receive individual instructor support.

\section{Virtual lab set-up for distance learning}
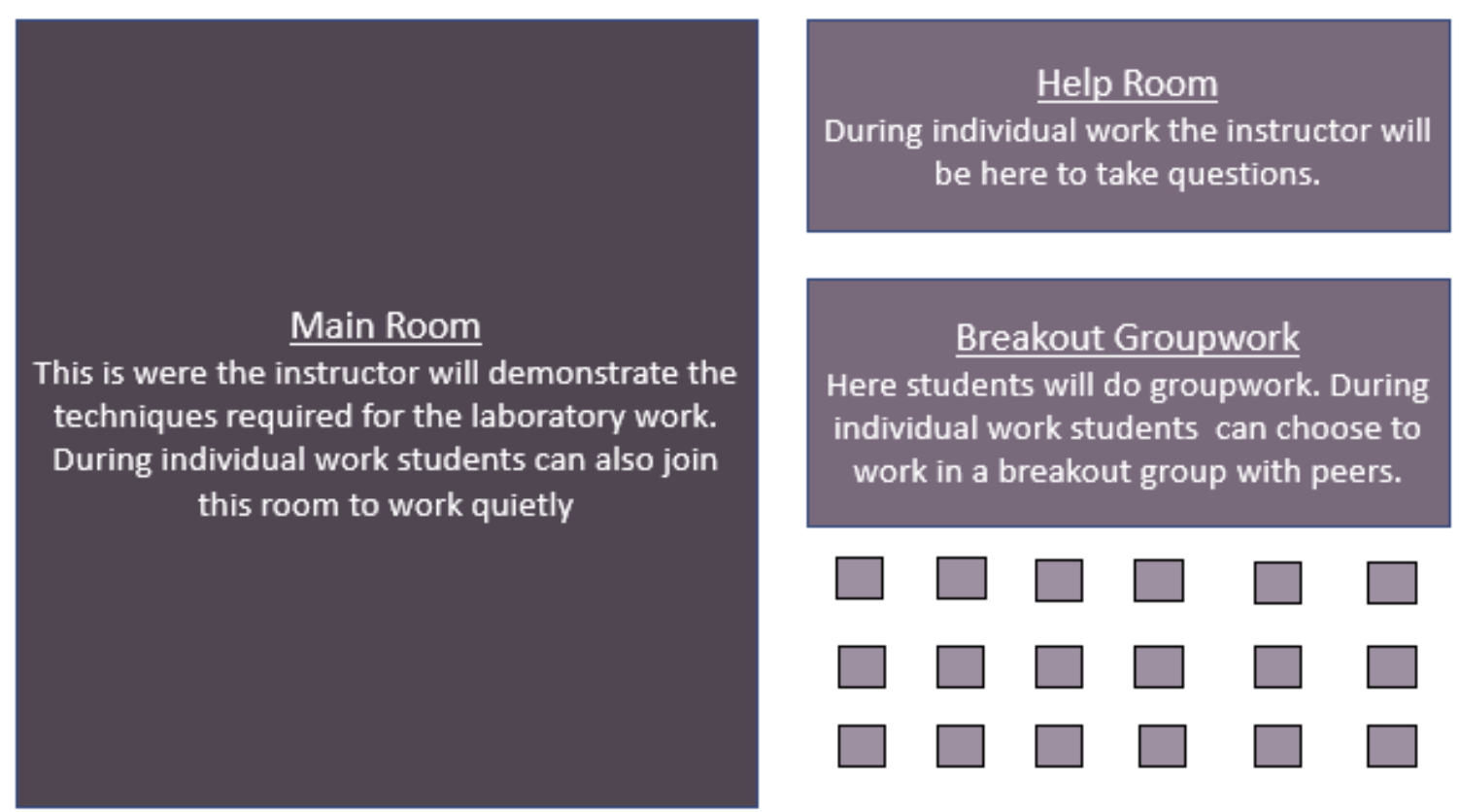

As this is a trailblazing approach for universities in the UK, there will be some operational and administrative factors to consider when delivering two simultaneous modes of delivery. Addressing these elements will therefore require collaborative cooperation across various CCCU departments. Consultation across academic and professional service departments has already begun and feedback thus far has indicated that operational aspects of delivery are feasible for CCCU to address (see Table 3 below for more details). 


\section{Initial Feedback from Collaborating Departments}

\section{Marketing and Communications}

\section{Further Market Research}

Student Recruitment Marketing

\section{Planning and Academic Administration}

- Additional resources needed to promote new mirrored delivery set-up, particularly need to promote the distance learning route.

- Ensure marketing campaign is embedded in the wider Marking plan of the university and individual Schools.

- Online prospectus required to reflect new programme structure

Registry

- Faculty Registrar will need to be consulted with throughout.

Admissions

\section{Undergraduate}

Admissions

Strategic Planning and Continuous Improvement

Student Systems

MOSI Programme

\section{Infrastructure Resources}

Information

Technology

\section{Delivery Resources}

\section{Library and Learning Resources}

\section{Learning and Teaching Enhancement}

\section{Internal Faculty requirements} campus delivery. week PT). Mentimeter etc).
- Each mode of delivery will need separate SITs codes.

- Different programme and module codes needed for the distance learning and on-

- Module codes can mirror each other for ease.

- Timetabling to mirror standards for on-campus delivery ( 2 days a week FT, 1 day a

- In SITS, distance learning delivery will be set up as a location, rather than a mode, with modules being assigned to the 'distance' location.

- IT have resources to fully support the distance learning route. IT can provide some 'out of hours' support and an information pack for distance learners.

- With the move to online teaching and learning necessitated by the Covid-19 pandemic, the Learning Skills Team is already prepared for remote information/digital literacy and academic skills session delivery.

- LTE can provide support in training staff and supporting the programme's use of our suite of virtual learning platforms (e.g., Teams, Blackboard Collaborate, Padlet,

- Distance learning students can also book 1:1 appointments with the LTE team for more assistance with online learning.

- LTE team can also develop online learning materials if there is a need for bespoke ones in addition the resources we already have on the Learning Skills Hub page.'

- Current admin support is sufficient. As numbers increase on the distance learning route, a small uplift in administrative support may be needed.

Table 3. Overview of the initial comments provided from consultation with various academic and professional service departments. 


\section{CONCLUSIONS}

The future of higher education lies within the capacity of universities to build adaptability into their operations (Reupert, 2020) and flexibility into their learning and teaching models (Baxter \& Atlas, 2020). Looking to the future, this shift from the traditional system will be one of the greatest strategical challenges facing CCCU and other higher educational institutes. To ensure CCCU is in a competitive position to thrive in this new era of flexible learning, the current report examined key external and internal environments of the university and the higher education sector. Through this analysis, the university's current position was evaluated, with findings highlighting critical areas of focus for the university. These results were used to inform the strategic recommendations generated above, proposing that CCCU implement an innovative approach to blended learning through the use of mirrored course delivery, with a focus in STEM subjects and level 4-5 courses. The report provided further details into the implementation plans for these provisions, along with a detailed overview into the justifications supporting the strategic recommendations generated.

\section{REFERENCES}

Aguilar, F.J. (1967) Scanning the Business Environment. New York: MacMillan Co.

Barney, J.B. (1991) 'Firm resources and sustained competitive advantage', Journal of Management, 17(1), pp. 99-120.

Bates, T. (2017) 'Tracking online and distance education in Canadian universities and colleges', International Journal of Educational Technology in Higher Education, 15(2), pp. $29-34$

Baxter, M., and Atlas, G. (2020) Five challenges to address during university strategy development. Available at: www.hepi.ac.uk/2019/06/29/five-challenges-toaddress-during-university-strategy-development/ (Accessed: 18 Apr 2021).

Becerra, M. (2009) Theory of the firm for strategic management: Economic value analysis. Cambridge: Cambridge University Press.

Fleisher, C. S., and Bensoussan, B. E. (2003) Strategic and competitive analysis: Methods and techniques for analyzing business competition. New Jersey, USA: Prentice Hall.

Hillman, N. (2020) The future of higher education after covid-19 [online]. Available at: 
https://www.hepi.ac.uk/2020/10/16/the-future-of-higher-education-after-covid/ (Accessed: 30 Mar 2021).

Humphrey, A. (2005) 'SWOT analysis for management consulting', SRI Alumni Newsletter, United States: SRI International.

Jisc (2020) Learning and teaching reimaged [online]. Available at:

https://www.jisc.ac.uk/learning-and-teaching-reimagined (Accessed: 18 Apr 2021).

Johnson, G., Scholes, K., Whittington, R. (2008) Exploring Corporate Strategy Text and Cases. $8^{\text {th }}$ edn. London: Pearson education.

LaConte, G. (2017) Multiply profit, help clients, and future-proof your accounting practice [online]. Washington, USA: Consult.

Lu, W. (2010) 'Improved SWOT approach for conducting strategic planning in the construction industry', Journal of Construction Engineering and Management, 136(6), pp. 1317-1328.

Murray, D., and Matthew, V. (2018) 'International learning communities in uncertain times', Journal of Higher Education Policy and Management, 40(6). pp. 517-519.

Porter, M. E. (1980) Competitive Strategy: Techniques for Analyzing Industries and Competitors. New York: Free Press.

Reupert, A. (2020) 'Change and (the need for) adaptability: The new normal', Promotion, Prevention and Early Intervention, 18(2), pp. 91-93.

Saloner, G., Shepard, A., and Podolny, J. (2001) Strategic management. Danvers: John Wiley \& Sons.

Vignali, C., and Vrontis, D. (2004) Global Marketing and Export Management. London: Foxwell and Davies.

Wernerfelt, B. (1984) 'A Resource-Based View of the Firm', Strategic Management Journal, 5(2). pp. 171-180.

Weihrich, H. (1982) 'The TOWS matrix - A tool for situational analysis', Long range planning, 15(2), pp. 54-66.

Yavuz, F., and Baycan T. (2013) 'Use of swot and analytic hierarchy process integration as a participatory decision-making tool in watershed management', Procedia Technology, 8, pp. $134-143$ 
